\title{
A CLINICAL STUDY OF MUCOCUTANEOUS MANIFESTATIONS OF HIV
}

\author{
S. B. Murugesh ${ }^{1}$, Nandini A. $\mathrm{S}^{2}$, Ravindra $\mathrm{K}^{3}$, Ramya $\mathrm{N}^{4}$
}

\section{HOW TO CITE THIS ARTICLE:}

S. B. Murugesh, Nandini A. S, Ravindra K, Ramya N. "A Clinical Study of Mucocutaneous Manifestations of HIV”. Journal of Evolution of Medical and Dental Sciences 2014; Vol. 3, Issue 44, September 15; Page: 10930-10945, DOI: $10.14260 /$ jemds/2014/3428

ABSTRACT: BACKGROUND AND OBJECTIVES: Mucocutaneous manifestations are extremely common and varied in HIV infected patients. The present study was done to know the overall prevalence of mucocutaneous manifestations in HIV infected patients and to know the frequency of individual manifestations. METHODS: A total of 150 HIV seropositive patients from voluntary counseling and testing center were included in the study. Detailed history, thorough physical examination and relevant investigations were done to confirm the mucocutaneous manifestations when present. RESULTS: Ninety two percent (92\%) of 150 positives had mucocutaneous manifestations at presentation. Majority (75.34\%) of the patients belonged to the age group $25-49$ years and male to female ratio was 1.08:1. Oral candidiasis was the most common (33.33\%) manifestation. Other common infectious conditions seen were HSV (16.67\%) dermatophytosis (12.67\%), genital candidiasis (9.33\%), herpes genitalis (10\%). Common non-infectious disorders included generalized xerosis and ichthyosis (14.66\%), generalized hyperpigmentation $(11.33 \%)$ and seborrheic dermatitis (6.67\%). Hair and nail changes included diffuse alopecia (18\%), trichomegaly (6.67\%) and melanonychia (32\%).Pruritic papular dermatitis was seen in 16\%. INTERPRETATION AND CONCLUSION: This study thus emphasizes the need for dermatological evaluation of all patients with HIV infection for early management and improved quality of life.

KEYWORDS: HIV, Mucocutaneous, Seropositive.

INTRODUCTION: The HIV (Human Immunodeficiency Virus) pandemic has taken the world by storm. Infection with HIV results in a slowly progressive systemic disease, characterized by gradual depletion of CD4 bearing T cells, opportunistic infections, neoplasms and degenerative neurologic disease resulting in the final stage of AIDS - Acquired Immuno Deficiency Syndrome.

AIDS was first recognized in the US in 1981 among previously healthy homosexual men, presenting with unexplained occurrences of Pneumocystis carinii pneumonia. In India, the onset of HIV epidemic was heralded by the detection of a case of HIV infection and a case of AIDS in Mumbai and Chennai respectively in 1986.

The HIV pandemic has given room for the raise of many emerging and re-emerging infections and has caused significant burden on the health sector, as well as on demography, economic and social systems. Once infected, the rate of progression of the disease depends on the viral characteristics and the host factors.

HIV infection practically affects all the tissues and organs of the body and skin - which acts as a mirror of a systemic disease is the most commonly affected organ in patients with HIV infection/AIDS. Cutaneous disorders have been recognized as important clues, not only in the diagnosis and the possible existence of an associated systemic illness, but also in some cases about the stage of involvement. 
For example, seborrheic dermatitis and zoster are early findings, while eosinophilic folliculitis, giant mollusc and large non-healing perirectal ulcers due to herpes simplex are seen in patients with CD4+ lymphocyte counts. With the advent of HAART (Highly Active Antiretroviral Therapy), skin disorders such as herpes zoster and mycobacterium aviumintercellula reinfection, may worsen when the immune status improves, a phenomenon known as the 'Immune reconstitution inflammatory syndrome'.

In general, skin infections and neoplastic condition in patients with HIV/AIDS may have atypical presentations and are aggressive and difficult to treat. Recognising HIV associated skin disease may lead to early HIV diagnosis and appropriate management, thereby reducing the morbidity, mortality and transmission of the disease. In this regard, the present study was undertaken to know the various mucocutaneous manifestations of HIV.

METHODS: The present study dealt with 150 HIV seropositive patients selected from Voluntary Counseling and Testing Centre (VCTC), Chigateri General Hospital attached to JJM Medical College, Davangere. This prospective study was undertaken from September 2004 - June 2006.

\section{INCLUSION CRITERIA:}

1. All Patients who presented to VCTC at CG hospital, irrespective of the department of referral, irrespective of the stage of HIV infection and irrespective of the presence or absence of dermatological complaints.

2. Patients above the age group of 1.5 years.

3. Patients on ART.

4. All of whom were diagnosed seropositive in response to the tests mentioned below.

\section{EXCLUSION CRITERIA:}

1. Pregnant women - as they presented to a separate centre (PPTCT) for their evaluation and management.

2. Children below 1.5 years, as they could not be diagnosed with HIV, with the procedure followed in VCTC.

3. Patients not willing for investigations.

In all the selected patients, a detailed history regarding the epidemiological aspects of the disease, and dermatological symptoms (when present) was taken and a thorough physical examination was performed, with emphasis on mucocutaneous manifestations.

After pretest counseling of the patients, blood samples were tested for anti-HIV antibodies as per strategy III (strategies of HIV testing by WHO) according to which serum reactive with COMB method (rapid test) was retested with a second rapid test - CAPILLUS method followed by a third rapid test - TRIDOT method. All of these 3 rapid tests are based on the presence of anti-HIV antibodies and agglutination with the same.

A patient was considered seropositive for HIV if he/she was tested positive for all three rapid tests. A patient who tested positive for the first two rapid tests and negative for the third was considered equivocal/borderline, and such individuals were retested after a few weeks. 
Clinical diagnosis was supplemented by relevant laboratory investigations such as:

1. $10 \% \mathrm{KOH}$ mount under the microscope for mycological examination. (tineae, candida)

2. Gram staining for diagnosis of gonococcal and non-gonococcal urethritis, mucopurulent cervicitis, chancroid, bacterial vaginosis, candidal infections and pyoderma.

3. Tzanck smear for genital herpes, herpes zoster, VZV infection,molluscum etc.

4. Wet mount for diagnosis of Trichomoniasis and Bacterial Vaginosis.

5. Leishman's staining for demonstration of Donovan bodies.

6. VDRL test.

7. Skin Biopsy in selected cases.

The data thus collected was tabulated and analysed.

RESULTS: HIV Seropositivity among patients attending VCTC, CG hospital from September 2004 June 2006: Of the 3490 individuals tested for HIV, $981-28.11 \%$ tested positive.

A total of 150 seropositive patients were examined, of whom 138 (92\%) presented with mucocutaneous manifestations. Among the 150 patients studied, 78(52\%) were male, $72(48 \%)$ were female. Majority of the patients were in the age group of 30-39 years (41.34\%) (Graph 1 )

EDUCATION: Majority of the patients - 59 out of 150 (39.33\%) were illiterates and around 54 (36\%) had undergone primary education. Very few- $14(9.4 \%)$ were educated more than $10^{\text {th }}$ standard. Heterosexual route was the most common route of transmission seen in 117 (78\%) followed by vertical in $11(7.33 \%)$ patients. (Table 1 and Graph 2)

A Majority of 57 patients, (38\%) gave a positive past history of Genital Ulcer Disease and 52 patients (34.66 \%) gave a history of herpes zoster. A total of 23 patients (15\%) had positive history of TB. (Table 2) Generalized itching was the most common dermatological presentation seen in $49(35 \%)$ of patients, followed by asymptomatic lesions in $36(24 \%)$ patients. (Table 3 )

\section{DERMATOLOGICAL MANIFESTATIONS:}

A. INFECTIOUS CONDITIONS: Among the viral infections, herpes simplex was the commonest seen in 25 patients, with genital herpes being more common than herpes labialis. EBV manifesting as Oral Hairy Leukoplakia (FIG 3) was seen in 2 of the patients. (Table 4)

Furuncle and ecthyma were the most common among bacterial infections with 4 of each followed by 2 of each of abscess, secondary infection and mycobacterium tuberculosis. (Table 5) Among the fungal infections, candidiasis was the most common with 65(43.33\%) patients affected by it, of which oral candidiasis accounted for $50(33.33 \%)$ patients followed by genital(vulvovaginal and balanoposthitis)affecting 14 patients (9.33\%) and 1 patient of candidal paronychia. (Table 6)

Dermatophytosis accounted for $28(12.67 \%)$ patients. A total of 30 patients $(20 \%)$ presented with genital ulcer, of which herpes genitalis was the commonest, seen in $15 \%$ patients. (Table 7) Scabies was the commonest parasitic infection seen in 7(4.66\%) of patients. (Table 8). 


\section{ORIGINAL ARTICLE}

B. NON-INFECTIOUS DERMATOSIS: Among non-infectious dermatosis, hyperpigmentation was the commonest manifestation seen in $6.67 \%$ of cases, followed by seborrheic dermatitis in $6.67 \%$ cases. (Table 9 \& Graph 3)

C. HAIR CHANGES: Hair changes included diffuse alopecia of the scalp seen in $27(18 \%)$ cases followed by trichomegaly in $10(6.67 \%)$ patients. (Graph 4)

D. NAIL CHANGES: A total of 67(44.67\%) patients had nail changes of which longitudinal melanonychia was the commonest seen in 34 patients, finger nail, being involved more commonly than toe nails. (Graph 5)

E. PRURITIC PAPULAR DERMATOSIS: A total of 24 patients(16\%) presented with pruritic papular dermatosis (FIG 7)

DISCUSSION: HIV SEROPOSITIVITY AMONG PATIENTS ATTENDING VCTC, CG HOSPITAL FROM SEPTEMBER-2004 TO JUNE-2006 - A total of 3490 persons were tested during this period, of whom $981(28.11 \%)$ were found to be seropositive for HIV.

PREVALENCE OF SKIN MANIFESTATIONS: A total of 150 seropositive (for HIV antibodies) patients were examined of whom 138 (92\%) had mucocutaneous lesions at presentation. Although in most of the Indian studies, the prevalence of mucocutaneous manifestations ranges from $40 \%$ to $66 \%$, the high prevalence (92\%) in the present study can be attributed to a larger number i.e. 67 (44.67\%) patients of AIDS, as skin manifestations are more common in advanced stages of HIV infection. The prevalence in present study is similar to the observation made by Coldiron et al. ${ }^{1}$

AGE AND SEX DISTRIBUTION: Among the 150 patients 78 (52\%) were male and 72 (48\%) were female. According to the present Global scenario UNAIDs 2 females are almost equally affected as males, of total HIV infected population (17.5 million women as compared to 20.5 million men). ${ }^{2}$

More number of patients was in the age group of 30-39 years (41.34\%). Nearly seventy five percent of the total affected patients belonged to the age group of 25-49 years which is a sexually active age group.

POSSIBLE ROUTE OF TRANSMISSION: In the present study the possible route of transmission in 117 patients $(78 \%)$ was through heterosexual route which is comparable to $75 \%$ heterosexual transmission worldwide. Homosexual transmission in males accounts for $3.33 \%$ in this study in contrast to $0.58 \%$ homosexual transmission in India (1998 scenario) ${ }^{3}$.This can be attributed to changing sexual patterns.

PAST HISTORY: A positive history of genital ulcer disease was present in $7(38 \%)$ patients and that of genital discharge disease in 14(9.33\%). This underscores the importance of STDs in the transmission of HIV and hence the importance of screening patients of STDs for HIV and also the importance of control and treatment of STDs in prevention of spread as implemented by NACO. 


\section{ORIGINAL ARTICLE}

PRESENTING COMPLAINTS/SYMPTOMS: Dermatological - Generalized itching was the most common dermatological symptom observed in 49(34.66\%) patients. Itching in HIV infected persons can be due to infectious causes (Dermatophytes, Parasites, bacterial folliculitis) or non-infectious causes (Xerosis, Icthyosis, exaggerated Insect bites, eosinophilic folliculitis etc). Pruritus represents hypersensitivity response to variety of antigens in patients with HIV infection. ${ }^{4}$

Burning sensation of mouth was seen in $18(12 \%)$ patients. This is a common symptom associated with oral candidiasis and also oral erosions/ulcers due to any other causes like aphthae, herpes simplex/ CMV infection. When Burning sensation of mouth (by candida) is associated with dysphagia patient is considered to have oesophageal candidiasis. ${ }^{3}$

1. INFECTIOUS CONDITIONS: VIRAL INFECTIONS: The present study values of viral infections (Molluscum contagiosum, Verrucae -warts, Herpes zoster (FIG 1) and OHL)are comparable to those of various studies. $., 6,7$

BACTERIAL INFECTIONS: A total of 14 patients (9.33\%) had bacterial infections which is comparable to other studies where the frequency varies from $7 \%$ of patients affected by staphylococcal infections to $25 \%$ of patients being affected by bacterial infections.

Two of the patients (1.33\%) had cutaneous tuberculosis (scrofuloderma) infection. On contrast Maniar et al, in their study of 20,520 HIV patients found cutaneous tuberculosis in $5.5 \%$ of patients. ${ }^{8} \mathrm{M}$. leprae infection was seen in 1 patient $(0.67 \%)$ who presented with type I lepra reaction (FIG 4). Although a significant association between leprosy and HIV infection has not been established, reversal reactions have been reported to be common in HIV infected leprosy patients.

In the present case the patient was started on ATT for pulmonary Koch, after 4 months of which he presented with type I lepra reaction. This may be attributed to the improvement in immunity following treatment of tuberculosis by ATT.

FUNGAL INFECTIONS: Candidiasis in various forms was seen in 65 patients (43.3\%), making it the most common opportunistic infection and the most common dermatological manifestation noted in the present study (FIG 11).

Candidal vulvovaginitis was seen in13 patients. The increased number can be attributed to large number of (48\%) female patients in the study group. Dermatophyte infections in various studies ranges from $5.2 \%^{4}$ to $37.5 \%{ }^{9}$ Shobana et al., found dermatophytosis in $13 \%$ patients which is in agreement with the present study. Onychomycosis was reported in $5 \% 5$ of patients with which the present study (6\%) is comparable. T.versicolor was seen in $2(1.33 \%)$ patients.

STDs (GUD): Among the genital ulcerative disorders, herpes genitalis was commonest, seen in 15 (10\%) patients, of whom one patient had chronic verrucous plaque, one patient had extensive vulval lesions associated with bilateral inguinal lymphadenopathy.

The present results is comparable to observations made by UdayKhopkar et al, 10 in which $10.5 \%$ patients had herpes genitalis. Chancroid was seen in $6(4 \%)$ patients of whom one patient had giant chancroid.

The frequency of chancroid reported in various studies ranges from $0.5 \%^{11}$ to $10.7 \%{ }^{12}$. 
Donovanosis was seen in $4(2.67 \%)$ patients of whom one male patient presented with extensive lesion involving the entire groin and perianal area (FIG 10). Study by Uday Khopkar et $\mathrm{al}^{10}$ showed donovanosis in $2 \%$ of patients which is comparable to the present study.

Though most of the other studies have no reported cases of donovanosis, $2.67 \%$ patients in the present study may be attributed to the relatively higher regional incidence of donovanosis. Secondary syphilis was seen in 5 (3.33\%) patients (FIG 5) of whom $3(2 \%)$ had maculopapular syphilis and 2 had malignant secondary syphilis (FIG 6) in the form of multiple ulcerations over skin, oral and genital mucosa associated with systemic features like fever and myalgia.

Secondary syphilis has been reported in $4 \%$ of patients in the study of Krishnan Raju et $\mathrm{al}^{13}$, which is comparable to the present study.

PARASITIC INFECTIONS: The incidence of scabies and pediculosis was comparable to other studies. ${ }^{4,11}$

2. NON-INFECTIOUS CONDITIONS: PAPULOSQUAMOUS: I. Seborrheic dermatitis was seen in 10 (6.67\%) patients. In various Indian studies, its occurrence varies from $3 \%$ to $21.4 \% .12,13$ Seborrheic dermatitis is considered to be a skin manifestation of advanced HIV infection. There are a number of factors that are probably important in the pathogenesis of the disease.

The number of pityriasisovale, P. ovale lipase activity, skin lipids, heredity, atmospheric humidity, and immune function of the body. In HIV infection, the decline of the immune system is the major cause of the high incidence of seborrheic dermatitis. ${ }^{14}$

Generalized xerosis was seen in $9.33 \%$ patients which is comparable to the study by Zancanaroet $\mathrm{al}^{5}$. Diffuse xeroderma or acquired ichthyosis are known to be closely correlated with more advanced phases of AIDS. ${ }^{15}$

Exfoliative dermatitis was seen in one patient secondary to rifampicin, administered as a part of ATT for pulmonary Kochs. Dermatitis subsided once rifampicin was stopped. This patient developed borderline tuberculoid Hansen's with type I reaction after 4 months of ATT (FIG 4). A single case of erythroderma has been reported by Uday Khoptar et al.10

PIGMENTARY CHANGES: Hyperpigmentation of skin was seen in $11.33 \%$ patients. Hyperpigmentation was generalized in most of the patients, more predominantly over sun exposed areas like face, upper back, forearms. In 2 of the patients facial hyperpigmentation alone was seen. Numerous factors are presumed as probable causes.

Drugs used for treatment and prophylaxis of OI, endocrine system disorders caused by HIV like adrenal insufficiency, long term sun exposure. Other illness like erythroderma, OIs such as TB, histoplasmosis, cryptococcosis and coccidiodomycosis can indirectly cause pigmentation. ${ }^{14}$

The importance of hyperpigmentation other than being one of the cutaneous markers of HIV and cosmetic significance is that it may be an indication to investigate for other OIs and endocrine causes.

VITILIGO: Vitiligo was seen in one patient. It was stable since many years with no increase in size or number. The association was probably co-incidental. 
APHTHAE: Aphthae were seen in 4 patients (2.67\%) of whom one had major aphthae involving palatal and tongue mucosae and 3 had minor aphthae involving labial buccal and tongue mucosae comparable to study by Shobhana et al.,11

DRUG RASH: Drug rash was seen in $6(4 \%)$. patients. Maculopapular rash was the commonest type found in 5 patients. Of the 6 patients, 5 patients were on ART. The other patient gave history of taking sulfamethaxazole - trimethoprim (TMP-SMX) tablets.

One patient on ART developed bullous drug rash, and another patient developed exfoliative dermatitis to rifampicin (mentioned in papulosquamous disorders).

Morbilliform drug eruptions are the most common presentation of drug hypersensitivity. TMP-SMX is the most common drug to cause adverse cutaneous drug eruption in HIV infected patients. Among ART drugs, maculopapular eruption is commonly associated with protease inhibitors and NNRTI.

Reported incidence of drug rash in various studies is 0.4 to $18 \%$ HIV infected persons. ${ }^{6,14,16}$ Vasculitis in the form of purpuric macules was seen in one patient etiology of which could not be identified with the limited resources and patient affordability. Pellagroid dermatitis was seen in one patient who was almost in terminal stages of the disease, emaciated and also was an alcoholic.

HAIR: Diffuse hair loss of scalp was seen in 27 (18\%) patients. Chronic, diffuse hair loss in HIV infected patients has been attributed to chronic HIV-1 infection itself and recurrent secondary infections, nutritional deficiencies, immunologic and endocrine dysregulation and exposure to multiple drugs.

Many cytokines including ILA, IL-6, TNF-a, and IL-10 increase in the mid to late stages of HIV1 disease, and these may have an effect on the follicle. In addition, in HIV-1 disease, a constant state of oxidative stress is present. Oxidative stress is a common factor in immediate anagen release telogen effluvium. ${ }^{17}$

Diffuse alopecia (telogen effluvium) in various studies ranges from $3.9 \%$ to $10 \% .{ }^{10,11}$ The increased prevalence (18\%) in the present study can be attributed to more number of patients in progressed stage of the HIV infection. Trichomegaly (elongation of eyelashes) was seen in 10 (6.67\%) patients. It was seen in both male and female patients (FIG 9).

Though previous reports have suggested longer eyelashes to be a marker for late - stage HIV disease ${ }^{18}$, the present study did not show any such correlation with the disease stage. It is suggested that viral activity plays an important role in the pathogenesis of trichomegaly. Some viral protein may be directly stimulatory to epidermal keratinocytes and pilosebaceous structures.

Straight hair or uncombable hair was seen in 7 (4.66\%) patients (FIG 8), where hair became thick, coarse and could not be combed properly. It was seen exclusively in males and all were in late stages of HIV infection. Straightening of hairs has been seen in upto $36 \%$ patients. $^{11}$

One male patient developed alopecia universalis. Patient was in AIDS, was on treatment for pulmonary tuberculosis. After 4 months there was spontaneous regrowth but partial and patchy. A similar case has been reported by Ostlereet al ${ }^{19}$.

One patient reported sudden graying of hair and one patient had pediculosis of scalp. The increased (sudden) graying may also be related to increased oxidative stress because melanocytes are much more sensitive to reactive oxygen species than keratinocytes. ${ }^{17}$ 
NAIL CHANGES: Longitudinal melanonychia was seen in $34(22.67 \%)$ patients. Finger nails involved in all and toe nails were involved in 11 patients. Proximal melanonychia was seen in $17(11.33 \%)$ patients with 2 of them having toe nail involvement also.

In HIV-1 disease, as patients become immunosuppressed, they also become immune activated as well as immune dysregulated which is supported by elevation of cytokines such as IL-1, 1L-6 and TNF-alpha, increased levels of which induce a febrile response through the hypothalamus, and the neuropeptide alpha-MSH.

Alpha-MSH when released from the anterior pituitary, is a potent natural antipyretic agent that antagonizes the fever induced by IL-1, IL-6 and TNF-alpha. IL-1 also up regulates alpha-MSH receptor expression by melanocytes as well as melanin production in the presence of MSH. AlphaMSH is a potent stimulant for melanocytic activation and pigmentation. ${ }^{20}$

Other features like icterus, longitudinal ridges and pallor were seen in one patient each. One patient showed hypo pigmented (white colored) band just distal to cuticle (of $2 \mathrm{~mm}$ width) in all finger nails, the cause of which could not be identified due lack of patient co-operation for nail biopsy. Clubbing was seen in fingers of 2 patients, both of whom were children.

PRURITIC PAPULAR DERMATITIS (PPD): PPD is a group of disorders, the classification of which is based on the aetiologies like bacterial folliculitis, pityrosporum folliculitis, eosinophillic folliculitis, exaggerated insect bite reaction, pruritic papular eruption of HIV. Biopsy could not be done as they did not give consents. Patients clinically presented with itchy papular lesions mainly over the extremities, chest, trunk and face.

A total of 24 patients (16\%) had PPD which was resistant to various modalities of treatment. Eosinophilic folliculitis was confirmed histopathologically in one patient, who had CD4 count of 54 whereas 6 patients showed nonspecific features.

SYSTEMIC MANIFESTATIONS: Tuberculosis was the most common systemic association with 30 patients suffering from various forms like pulmonary (21 patients), pleural and abdominal (5 patients) and CNS involvement (4 patients).

Overlap between AIDS and TB epidemic adds to increased TB morbidity. HIV is the most powerful factor known to increase the risk of progression of TB infection in persons dually infected with HIV and M. tuberculosis, the lifetime risk of developing TB is about $50 \%$.

LIMITATION OF THE STUDY: No correlation with CD4 count could be made as the facility was not available in the hospital the study was done.

\section{REFERENCES:}

1. Coldiron BM, Bergstresser PR. Prevalence and clinical spectrum of skin disease in patiens infected with human immunodeficiency virus. Arch Dermatol 1989; 125: 357-61.

2. AIDS epidemic update: December 2005. [Online]. 2005 [cited 2005 Dec.1]; [3 screens]. Available from:_URL: http:// www.unaids.org/.

3. Joshi PL, Shaukat M, Sengupta D, Mishra SN, Chugh S. Baveja UK, et al, editors. Specialist's training and reference module 2000. New Delhi: National AIDS control organization; 2000. 
4. Shah H, Lakhani J, Trivedi S. Cutaneous manifestations in HIV seropositive cases in a rural hospital of Gujarat. Indian J Sex Transm Dis 1998; 19 (2): 95-97.

5. Zancanaro PCQ, Mamelak AJ, and Nguyen R< Martins CR. Cutaneous manifestations of HIV in the era of highly active antiretroviral therapy: An institutional urban clinic experience. J Am Acad Dermatol 2006; 54: 581-8.

6. Smith KJ, Skelton HG, Yeager J, Ledsky R, McCarthy W, Baxter D, et al. Cutaneous findings in HIV1 positive patients: A 42 - month prospective study. J Am Acad Dermatol 1994; 31: 746-54.

7. Goodman DS, Teplitz ED, Wishner A, Klein RS, Burk PG, Herhenbaum E. Prevalence of cutaneous disease in patients with acquired immunodeficiency syndrome (AIDS) or AIDS - related complex. 1 Am Acad Dermatol 1987; 17: 210-20.

8. ManiarJK. The HIV/AIDS epidemic in India-real challenge for Dermatovenereologists in the new Millenium, 29th National Conference of IADVL, 1-4 February 2001, Agra.

9. Bhandary PG, Kamath KN, Pai GS, Rao G. Cutaneous manifestations of HIV infection. Ind J Dermatol Venereol Leprol 1997; 63: 35-7.

10. Khopkar U, Raj S, Sukthankar A, Kulkarni MG, Wadhura SL. Clinical profile of HIV infection. Ind J of Dermatol, Venereol and Leprol 1992; 58: 155-58.

11. Shobana A, Gucha SK, Neogi K. Mucocutaneous manifestations of HIV infection. Indian J Dermatol Venereol Leprol 2004; 70: 82-6.

12. Kar HK, Narayan RJ. Gautam RK, Jain RK, Doda V, Sengupta D, et al. Mucocutaneos disorders in HIV positive patients. Ind Dermatol Venereol Leprol 1996; 62: 283-5.

13. Raju PVK, Rao GR, Ramani TV, Vandana S. Skin disease: Clinical indicator of immune status in HIV infection. Int J Dermatol 2005; 44: 646-49.

14. Montazeri A, Kanitakis J, Bazeixs J. Psoriasis and HIV infection. Int J Dermatol 1996; 35: 475492.

15. Rosatelli JB, Machado AA, Roseline AM. Dermatoses among Brazilian HIV-positive patients:Corelation with the evolutionary phases of AIDS. Int J Dermatol 1997; 36: 729-34.

16. Spira R, Mignard H, Doutre MS, Morlat P, Dabis F. Prevalence of cutaneous disorders in a population of HIV — infected patients. Arch Dermatol 1998; 134: 1208-12.

17. Smith KJ, Skelton HG, DeRusso D, Sperling L, Yeager J, Wagner KF, et al. Clinical and histopathologic features of hair loss in patients with HIV-1 infection. J Am Acad Dermatol 1996; 34: 63-8.

18. Mirmirani P, Hessol NA, Maurer TA, Berger TG, Greenblatt RM, Price VH. Hair changes in women from the women's interagency HIV study. Arch Dermatol 2003; 139: 105-06.

19. Ostlere. Alopeicauniversalis in a patient seropositive for the human immunodeficiency virus. J Am Acad Dermatol 1993; 27: 630-1.

20. Smith KJ, Skelton HG, Heimer W, Baxter D, Angritt P, Frisman D, et al. Melanocytic activation in HIV-1 disease: HMB-45 Staining in common acquired nevi. J Am Acad Dermatol 1993; 29: 53944. 
ORIGINAL ARTICLE

\begin{tabular}{|c|c|c|c|c|}
\hline & MALE & FEMALE & TOTAL & PERCENTAGE \\
\hline Heterosexual & 55 & 62 & 117 & 78.00 \\
\hline Homosexual & 5 & 0 & 5 & 3.33 \\
\hline Vertical & 7 & 4 & 11 & 7.33 \\
\hline Blood Transfusion & 0 & 3 & 3 & 2 \\
\hline IV Drug use & 0 & 0 & 0 & 0 \\
\hline Unknown & 11 & 3 & 14 & 9.34 \\
\hline TOTAL & $\mathbf{7 8}$ & $\mathbf{7 2}$ & $\mathbf{1 5 0}$ & $\mathbf{1 0 0}$ \\
\hline TABLE 1: POSSIBLE ROUTE OF TRANSMISSION
\end{tabular}

\begin{tabular}{|c|c|c|}
\hline CONDITION & NUMBER & PERCENTAGE \\
\hline Herpes Zoster & 38 & 25.33 \\
$>2$ episodes & 14 & 9.33 \\
\hline GUD & 57 & 38 \\
\hline GDD & 14 & 9.33 \\
\hline TB- Pulmonary & 22 & 14.66 \\
Extra pulmonary(Pleural) & 1 & 0.66 \\
\hline Herpes labialis & 2 & 1.33 \\
\hline
\end{tabular}

TABLE 2: PAST HISTORY

\begin{tabular}{|l|c|c|}
\hline \multicolumn{1}{|c|}{ SYMPTOM } & NUMBER & PERCENTAGE \\
\hline Generalized Itching & 49 & 34.66 \\
\hline Skin lesions(painful/asymptomatic) & 36 & 24 \\
\hline Burning sensation of mouth with dysphagia & 18 & 12 \\
\hline Genital lesions & 24 & 16 \\
\hline
\end{tabular}

TABLE 3: PRESENTING SYMPTOMS - DERMATOLOGICAL SYMPTOMS

\begin{tabular}{|l|c|c|}
\hline & Number & Percentage \\
\hline HSV - LABIALIS & 10 & 6.67 \\
\hline HSV - GENITALIS & 15 & 10.00 \\
\hline HERPES ZOSTE & 6 & 4 \\
\hline$<2$ dermatome & 4 & 2.67 \\
\hline Multidermatome & 1 & 0.67 \\
\hline Disseminated & 1 & 0.67 \\
\hline MOLLUSCUM CONTAGIOSUM & 14 & 9.33 \\
\hline Extragenital & 9 & 4.66 \\
\hline Genital & 5 & 4.67 \\
\hline VERRUC & 14 & 9.33 \\
\hline Extragenital & 7 & 4.66 \\
\hline Genital & 7 & 4.67 \\
\hline OHL & 2 & 1.33 \\
\hline \multicolumn{2}{|c|}{ TABLE 4: VIRAL INFECTIONS } \\
\hline \multicolumn{2}{|c|}{} \\
\hline \multicolumn{2}{|c|}{} \\
\hline
\end{tabular}


ORIGINAL ARTICLE

\begin{tabular}{|c|c|c|}
\hline BACTERIAL INFECTIONS & NO. OF CASES & PERCENTAGE \\
\hline Furuncle & 4 & 2.67 \\
\hline Ecthyma & 4 & 2.67 \\
\hline Impetigo & 1 & 0.67 \\
\hline Cellulitis & 1 & 0.67 \\
\hline Abscess & 2 & 1.33 \\
\hline Secondary infection & 2 & 1.33 \\
\hline \multicolumn{3}{|l|}{ Mycobacterial } \\
\hline $\begin{array}{l}\text { Tuberculosis } \\
\text { (scrofuloderma) }\end{array}$ & 2 & 1.33 \\
\hline Leprosy & 1 & 0.67 \\
\hline
\end{tabular}

\begin{tabular}{|c|c|c|}
\hline FUNGAL INFECTIONS & NO. OF CASES & PERCENTAGE \\
\hline Candidiasis & 65 & 43.33 \\
\hline Oral & 50 & 33.33 \\
\hline Thrush & 31 & 20.67 \\
\hline Atrophic & 5 & 3.33 \\
\hline MRG & 5 & 3.33 \\
\hline Perleche & 9 & 6.00 \\
\hline Genital & 14 & 9.33 \\
\hline Paronychia & 1 & 0.67 \\
\hline Dermatophytes & 19 & 12.67 \\
\hline T. corporis & 9 & 6.00 \\
\hline T. cruris & 7 & 4.66 \\
\hline Majocchi's granuloma & 2 & 1.33 \\
\hline T mannum & 1 & 0.67 \\
\hline Onychomycosis & 9 & 6.00 \\
\hline T. versicolor & 2 & 1.33 \\
\hline
\end{tabular}

\begin{tabular}{|l|c|c|}
\hline & NO. OF CASES & PERCENTAGE \\
\hline Syphilis & & \\
\hline Secondary & 3 & $2.00 \%$ \\
\hline Malignant Secondary & 2 & 1.33 \\
\hline Chancroid & 6 & 4.00 \\
\hline Donovanosis & 4 & 2.67 \\
\hline Herpes genitalis & 15 & 10.00 \\
\hline \multicolumn{2}{|c|}{ TOTAL TABLE 7: STDs (GUD) } \\
\hline \multicolumn{2}{|c|}{} \\
\hline
\end{tabular}




\begin{tabular}{|c|c|c|}
\hline & NO. OF CASES & PERCENTAGE \\
\hline Scabies & 7 & 4.66 \\
\hline Pediculosis & 1 & 0.67 \\
\hline TOTAL & $\mathbf{8}$ & $\mathbf{5 . 3 3}$ \\
\hline \multicolumn{2}{|c|}{ TABLE 8: PARASITIC INFECTIONS }
\end{tabular}

\begin{tabular}{|l|l|l|l|}
\hline & \multicolumn{2}{|c|}{ NO. OF CASES } & PERCENTAGE \\
\hline I & PAPULOSQUAMOUS & & \\
& 1. Seborrheic Dermatitis & 10 & 6.67 \\
& 2. Generalised xerosis & 14 & 9.33 \\
& 3. Icthyosis & 8 & 5.33 \\
& 4. Exfoliative Dermatitis & 1 & 0.67 \\
\hline II & PIGMENTARY DISORDERS & & \\
& 1. Hyperpigmentation & 17 & 11.33 \\
& 2. Vitiligo & 1 & 0.67 \\
\hline III & APHTHAE & 1 & \\
& 1. Major & 3 & 0.67 \\
& 2. Minor & 6 & 2.00 \\
\hline IV & DRUG RASH & 2 & 4.00 \\
\hline V & OTHERS & 1 & 1.33 \\
& 1. Miliaria & 1 & 0.67 \\
& 2. Vasculitis & Pellagroid Dermatitis & 0.67 \\
& 3. TABLE 9: NON-INFECTIOUS DERMATOSIS \\
\hline
\end{tabular}

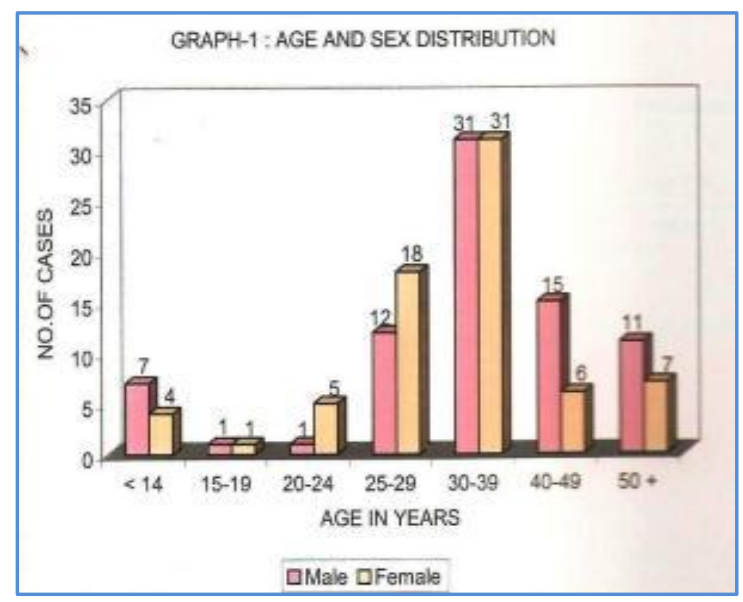

\section{GRAPH 1: AGE AND SEX DISTRIBUTION}




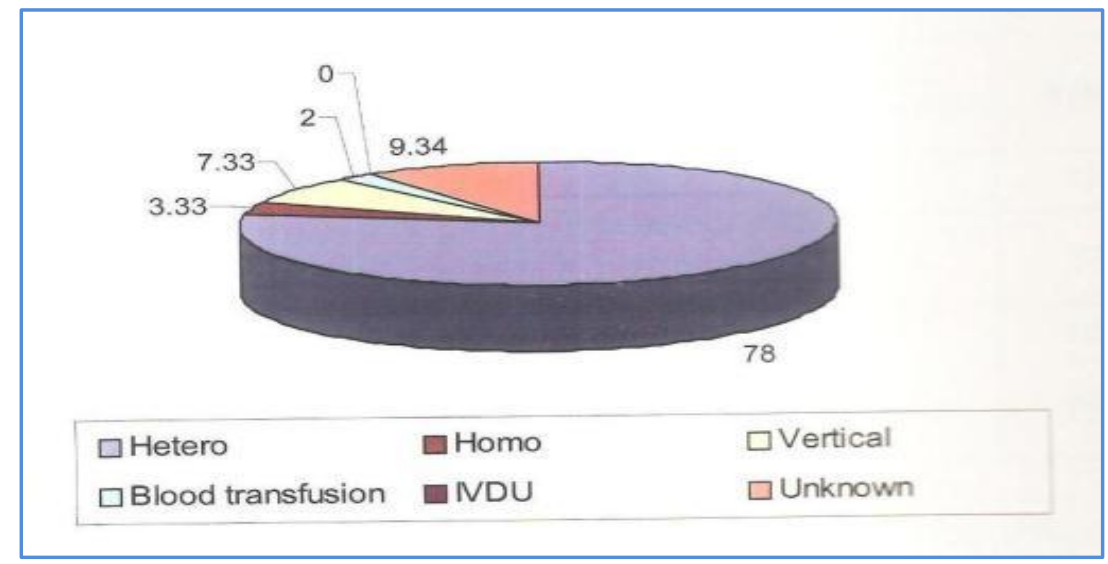

GRAPH 2: POSSIBLE ROUTE OF TRANSMISSION

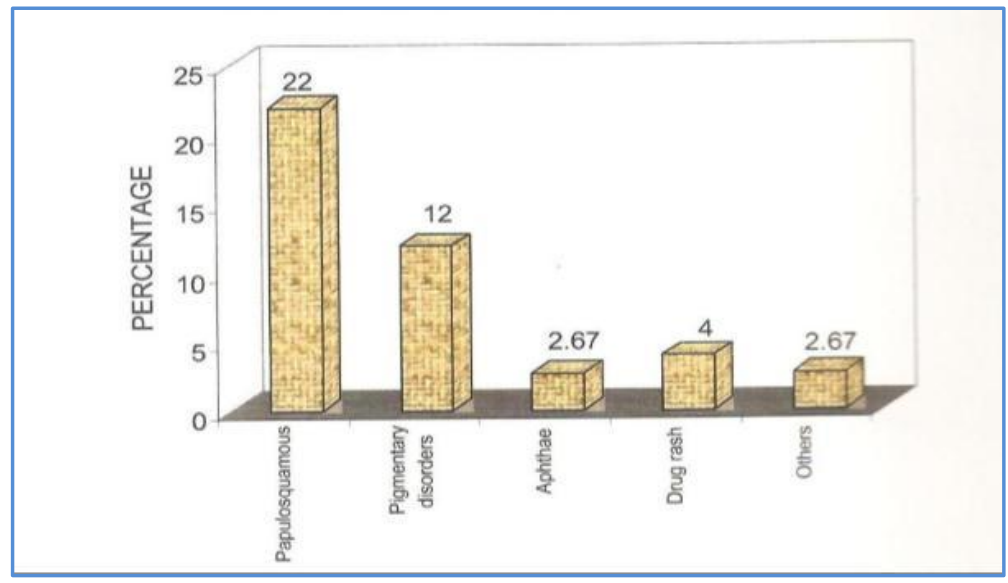

GRAPH 3: NON - INFECTIOUS DERMATOSES

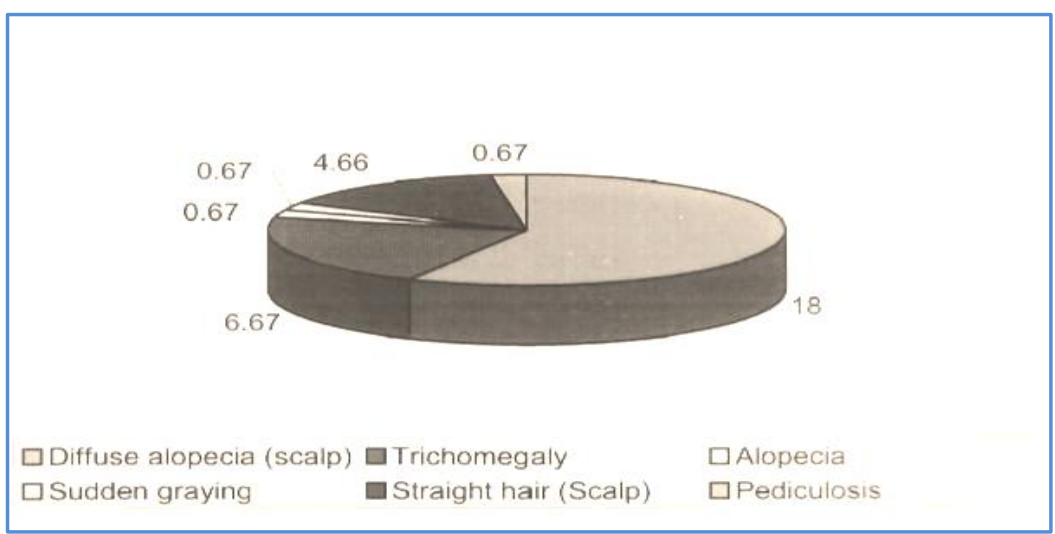

GRAPH 4: HAIR CHANGES 


\section{ORIGINAL ARTICLE}

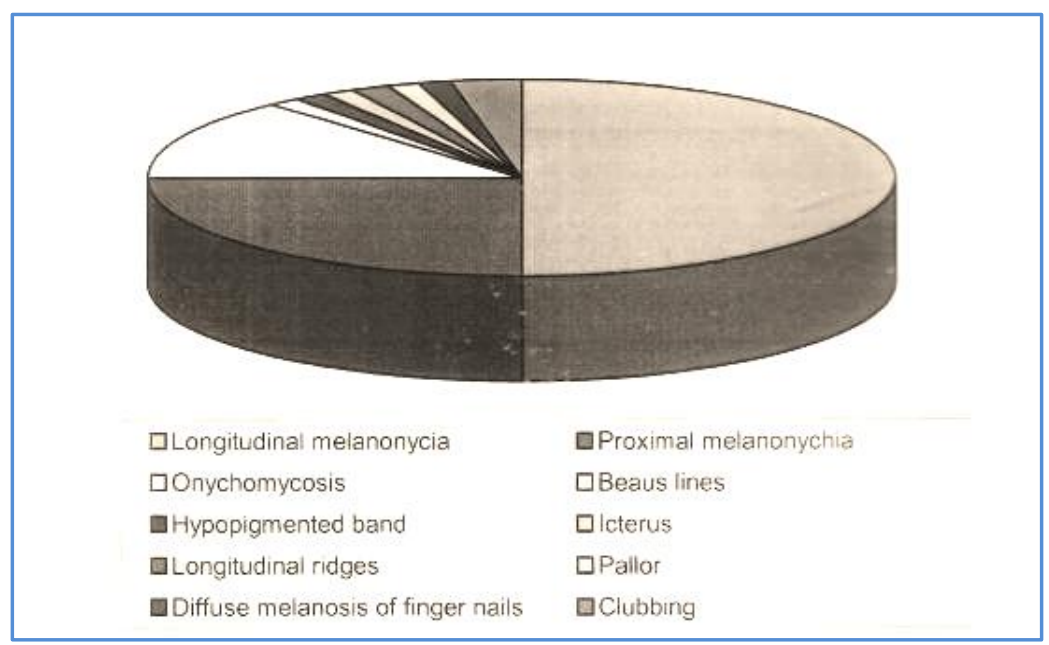

\section{GRAPH 5: NAIL CHANGES}

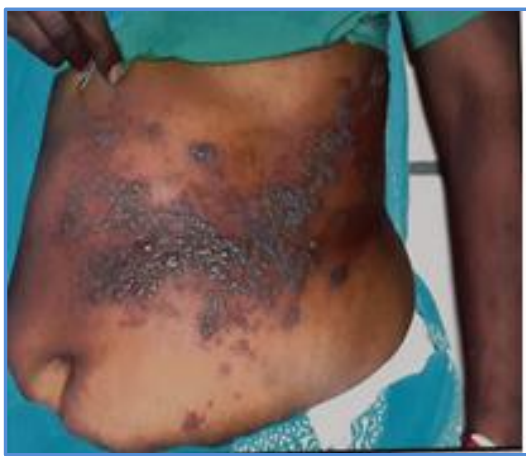

FIG. 1: DISSEMINATED HERPES ZOSTER

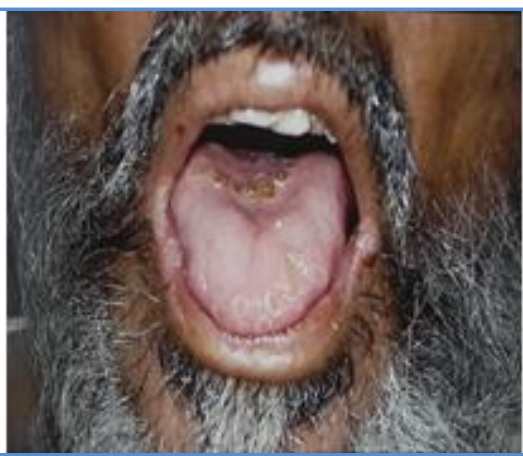

FIG. 2: HERPETIC STOMATITIS

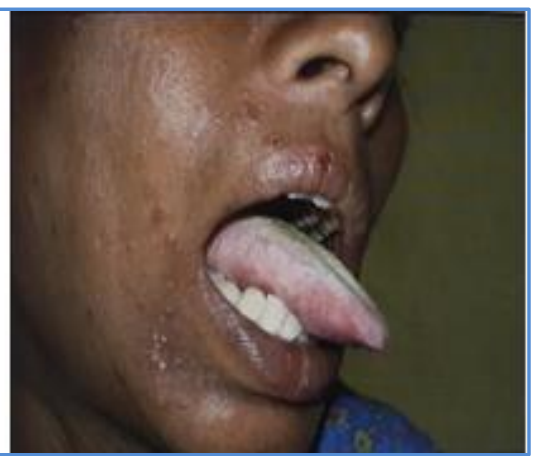

FIG. 3: ORAL HAIRY LEUKOPLAKIA

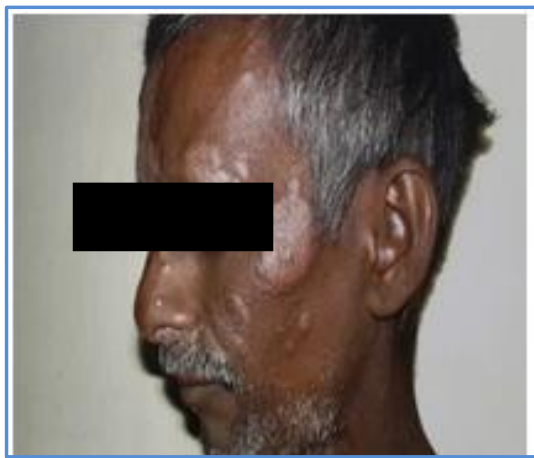

FIG. 4: BT HANSENS WITH TYPE I LEPRA REACTION

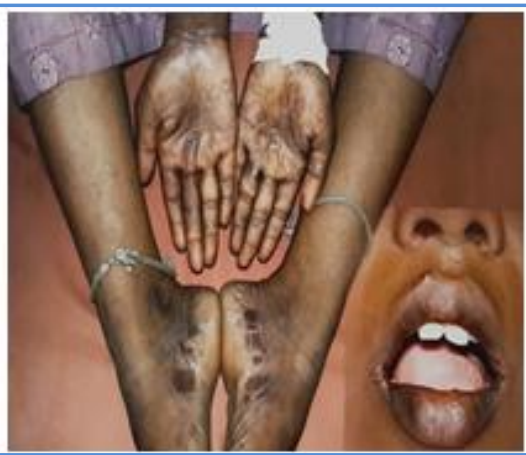

FIG. 5: SECONDARY SYPHILIS WITH SPLIT PAPULE

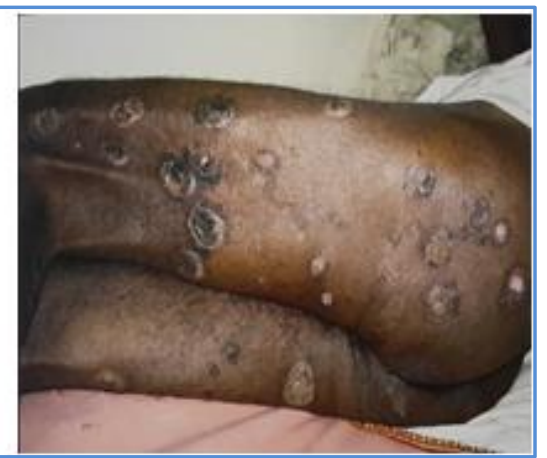

FIG. 6: MALIGNANT SECONDARY SYPHILISF 


\section{ORIGINAL ARTICLE}

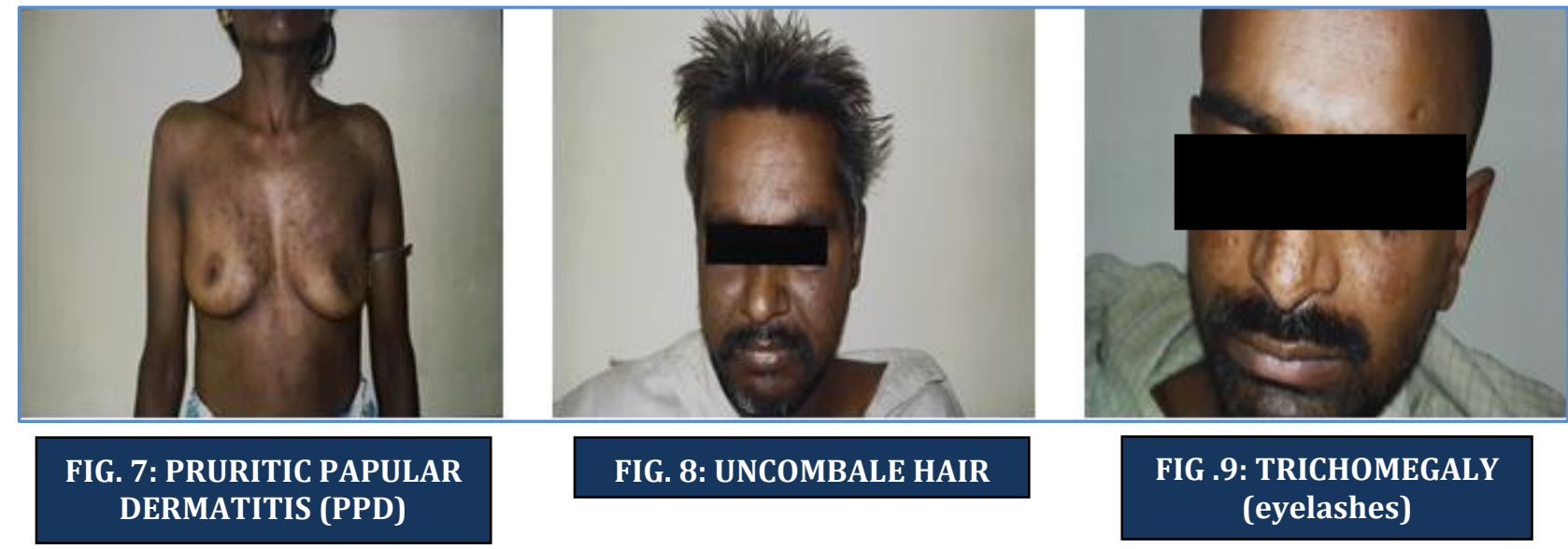

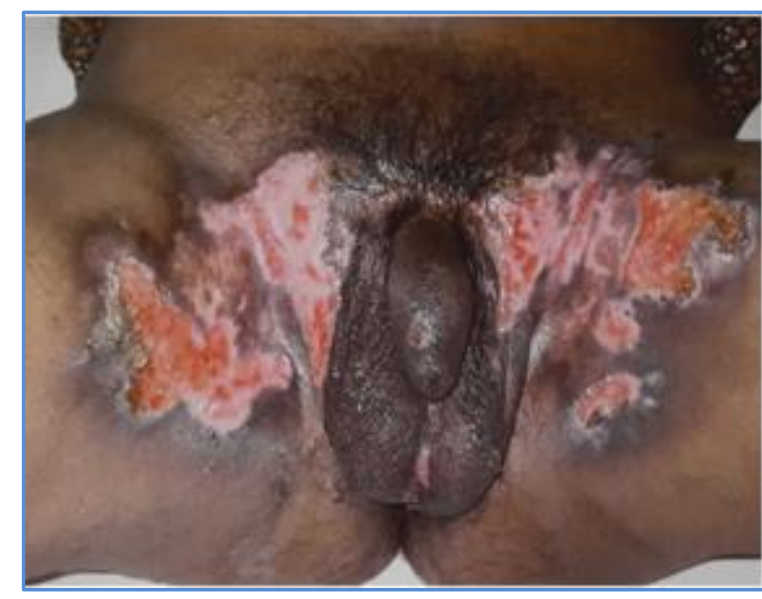

FIG. 10: DONOVANOSIS

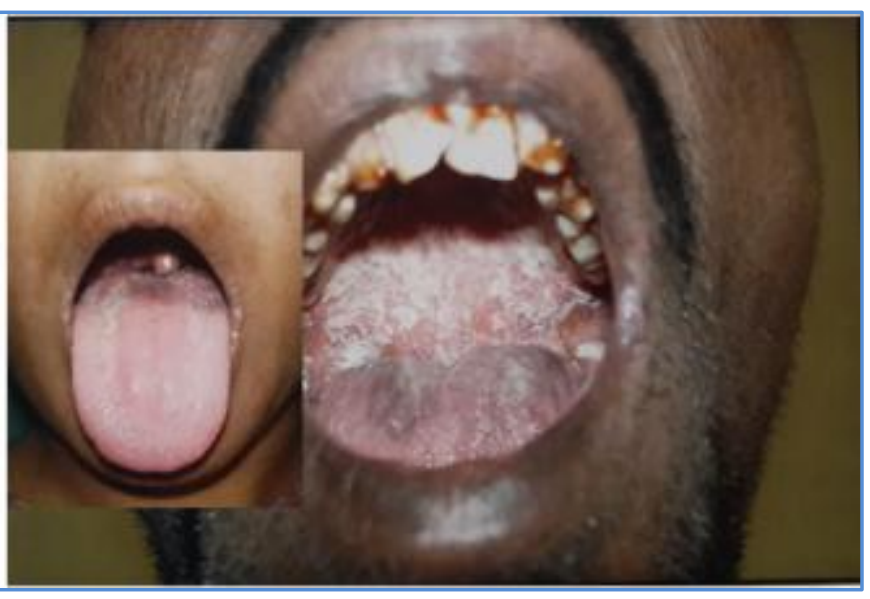

FIG. 11: HYPERPLASTIC CANDIDIASIS. INSET: ATROPHIC CANDIDIASIS 


\section{AUTHORS:}

1. S. B. Murugesh

2. Nandini A. S.

3. Ravindra K.

4. Ramya N.

\section{PARTICULARS OF CONTRIBUTORS:}

1. Professor \& HOD, Department of Dermatology, JJM Medical College, Davangere.

2. Assistant Professor, Department of Dermatology, Kempegowda Institute of Medical Sciences, Bangalore.

3. Professor, Department of Dermatology, JJM Medical College, Davangere.

4. Post Graduate, Department of Dermatology, Kempegowda Institute of Medical Sciences, Bangalore.

\section{NAME ADDRESS EMAIL ID OF THE CORRESPONDING AUTHOR:}

Dr. Nandini A. S,

Assistant Professor,

Department of Dermatology,

Kempegowda Institute of Medical Sciences,

Bangalore.

Email:drnandinias2002@yahoo.com

Date of Submission: 26/08/2014.

Date of Peer Review: 27/08/2014.

Date of Acceptance: 09/09/2014.

Date of Publishing: 15/09/2014. 